\title{
VILLA SPRING HILL COMO EXPRESIÓN DEL PATERNALISMO DE LA EMPRESA NACIONAL DEL PETRÓLEO (ENAP) EN EL GRAN CONCEPCIÓN, CHILE*
}

\author{
VILLA SPRING HILL AS AN EXPRESSION OF THE PATERNALISM \\ OF THE NATIONAL PETROLEUM COMPANY (ENAP) IN GRAN \\ CONCEPCIÓN, CHILE
}

\author{
LEONEL PÉREZ ${ }^{\star \star}$, RODRIGO HERRERA*** ${ }^{\star * A B L O ~ F U E N T E S ~}{ }^{\star * * *}$
}

Resumen: En Chile, en torno al río Biobío, en la región homónima, durante la segunda mitad del siglo XX, se materializaron conjuntos habitacionales distanciados, pero conectados a sus plantas industriales. Uno relevante es Villa Spring Hill, barrio situado en el municipio de San Pedro de la Paz, aledaño a la ciudad de Concepción, avalado por la Empresa Nacional de Petróleo (ENAP). Uno de los objetivos de la investigación fue indagar en la conformación de los espacios habitacionales construidos por la industria fordista estatal, en tanto que formas de paternalismo industrial, explorando su valoración como patrimonio urbano del Gran Concepción. Se reunió información a partir de revisión documental y otras fuentes primarias, además de entrevistas a vecinos y ex residentes de la villa, antiguos trabajadores de la Refinería ENAP. El análisis integra las variables de la configuración espacial y rescata valoraciones y experiencias de sus habitantes. Se concluye destacando la unión de intereses empresa-trabajadores y la idea de una gran familia refinera, donde la industria ocupa un lugar no preponderante en el desenvolvimiento de lo cotidiano, aunque relevante en su gestación y concreción.

PALABRAS ClAVE: Vivienda obrera, paternalismo industrial, hábitat colectivo, refinería de petróleo.

ABSTRACT: During the second half of the twentieth century, housing complexes were constructed near the Biobío River, in the homonymous region of Chile, which while distant from industrial plants nevertheless maintained a close connection. Villa Spring Hill, a neighborhood located in the municipality of San Pedro de la Paz, near the city

\footnotetext{
* Agradecimientos al Proyecto FONDECYT Regular 1171100 y al Proyecto CONICYT/PIA SOC 1403.

** Doctor en Urbanismo. Profesor Asociado del Departamento de Urbanismo e investigador del Centro CEDEUS, Universidad de Concepción, Concepción, Chile. Correo electrónico: leperez@udec.cl

*** Doctor en Antropología Social y Cultural. Investigador en la Vicerrectoría de Vinculación con el Medio, Universidad de Concepción, Concepción, Chile. Correo electrónico: rherrerao@udec.cl

$* * * *$ Doctor en Arquitectura. Investigador y Profesor Asociado del Departamento de Diseño y Teoría de la Arquitectura, Universidad del Bío-Bío, Concepción, Chile. Correo electrónico: pfuentes@ ubiobio.cl
} 
of Concepción, and supported by the National Petroleum Company (ENAP), is an emblematic case. One of the objectives of this study is to investigate the configuration of residential spaces built by the state Fordist industry as forms of industrial paternalism, exploring their valuation as part of the urban heritage of Gran Concepción. Information was gathered from documentary research and other primary sources, in addition to interviews with neighbors and former residents who worked at the ENAP refinery. The analysis integrates the variables of spatial configuration and recovers the assessments and experiences of its inhabitants. It concludes by highlighting the union of business-worker interests and the idea of a large "refining" family, in which the industry does not play a predominant role in everyday life, although it is relevant in the community's inception and development.

KEYWORDs: Worker housing, industrial paternalism, collective habitat, oil refineries.

Recibido: 27.04.18. Aceptado: 24.10 .19

\section{INTRODUCCIÓN}

E n Chile, la producción de conocimiento sobre los espacios productivos y residenciales construidos por la industria es un proceso relativamente reciente, y mas aún la investigación sobre su puesta en valor. Se destacan los estudios de Garcés (1999) para las ciudades del salitre y del cobre (Garcés, 2003; Garcés, Cooper y Baros, 2007) en el Norte Grande de Chile, y los trabajos de Venegas (1998) y Godoy (2015) para la cuenca del carbón en la Región del Biobío. Para el sector hidrocarburos, pioneros fueron los trabajos de Hecht (2002) y Domínguez (2011), centrados en la construcción del poblado de Cerro Sombrero en la Región de Magallanes por parte de la ENAP.

En ellos inciden las formas de paternalismo ejercidas durante los procesos de industrialización y radicación de la población. En general, se ha investigado poco el espacio productivo, social y urbano emergido del modelo fordista promovido por el Estado chileno al comenzar la segunda mitad del siglo XX, sobre la opción de conformar ciudad constituyendo barrios, y su cruce con las formas ejercidas desde la propia industria para conformar morfologías sociales adecuadas a las formas urbanísticas implementadas. Esto resulta relevante porque los registros, investigaciones y valoración del espacio productivo, social y urbano han centrado sus análisis en aquellos conjuntos urbanos de mayor escala, que fueron creados directamente por la gran industria hasta la primera mitad del siglo XX, siguiendo el modelo de company town.

Este caso releva Villa Spring Hill, un conjunto habitacional auspiciado conjuntamente por la ENAP y sus trabajadores en la década de 1970. Des- 
de un punto de vista metodológico, se aborda primero su configuración espacial, a partir de la cual se advierten las valoraciones sociales atribuidas por los habitantes. Se recurrió a información documental en archivos municipales y registros particulares de participantes en la obra. Para el trabajo cualitativo se realizaron entrevistas abiertas individuales y grupales a vecinos de la Villa, accediendo a valoraciones de quienes recibieron sus viviendas en cada una de las diferentes etapas de construcción. También se consultó a quienes ya no habitan la Villa y a personal de apoyo técnico que la empresa proveyó para colaborar en la construcción de las primeras etapas de urbanización. Se pesquisó el ingreso a la empresa, el acceso a la vivienda y el devenir de la vida cotidiana en la Villa. El diálogo fue reforzado con fotografías y planos que los vecinos conservaban. Además, en base a la revisión de bibliografía específica que privilegió el contexto chileno, se contextualizaron y consideraron las prácticas de paternalismo, y los criterios de urbanización, edificación y habitación de sectores ligados al desarrollo industrial.

En este caso, el objetivo se centró en investigar la configuración de uno de los espacios residenciales construidos por ENAP como expresión de paternalismo de la industria estatal, explorando su valoración como patrimonio urbano del Gran Concepción. No solo desde una perspectiva territorial o urbanística, sino también simbólica, por la complejidad implícita que conlleva construir espacios sociales que alojan significados sobre la memoria colectiva y las prácticas sociales cotidianas.

\section{PATERNALISMO INDUSTRIAL COMO MARCO DE REFERENCIA}

Como señala Vergara (2013), el paternalismo industrial puede entenderse como una experiencia transnacional de fines del siglo XIX y primera mitad del siglo XX, porque asume que a lo largo de América Latina los procesos de industrialización y modernización requerían 'nuevas' prácticas empresariales que se tradujeran en 'nuevos' hábitos, disciplinas y normas. En su ejercicio, permitían el desarrollo de otro tipo de habilidades y técnicas por parte de los trabajadores, para responder a las presiones del modelo capitalista. El desafío era consolidar una mano de obra moderna que acompañara la expansión del sector industrial. Para ello, era necesario hacer más eficiente el reclutamiento laboral, disminuir el absentismo y aumentar la capacitación de la mano de obra, consiguiendo así el aumento de la productividad. Estos esfuerzos no serían suficientes si no iban acompañados por beneficios sociales y servicios urbanos que acabarían creando mano 
de obra estable, dócil y productiva. Desde el punto de vista urbano, todo ello se cristalizó en la construcción de modernos campamentos mineros y barrios obreros. Dicho así, el paternalismo industrial se entiende como un conjunto de mecanismos de control destinados a cubrir una serie de demandas sociales de los trabajadores: vivienda, salud, educación, entretención y algunos aspectos de sociabilidad y uso del tiempo de ocio (Godoy, 2015). Su clave será regular el trabajo incidiendo en los tiempos y usos de los períodos de no-trabajo (Sierra, 1984, 1985, 1990). Así, se conseguía disciplinamiento social sujeto a la adhesión, consenso y aceptación de un conjunto de reglas por parte de los trabajadores. Este se traducía en participación del trabajador a través de su inserción en marcos de sociabilidad propuestos, con lo que el conjunto social respondía a relaciones aparentemente armónicas, donde cada quien se comportaba de acuerdo a lo tolerable para el resto del conjunto (Mantecón, 2010).

Así se entiende que las prácticas paternalistas fueran más allá de la conquista y definición de espacialidades funcionales que encontraban en el urbanismo un aliado (Godoy 2015). Crearon igualmente otros caminos para la gestación de una sociabilidad obrera que incidió en su mayor productividad, revistiendo de sensibilidad social afanes de control social, a través del trato directo con el jefe o patrón, o desde las oficinas de bienestar dispuestas por las empresas para los trabajadores.

Lo innovador en el caso latinoamericano fue cuando alrededor de la década del 40 del siglo pasado, el Estado ingresa en algunos países como actor relevante al mercado productor instaurando políticas de paternalismo industrial que articulan lo laboral y lo familiar. La industria, a través de las visitadoras sociales o los departamentos de bienestar, se introduce en la intimidad de la vida del trabajador, para domesticar sus hábitos, compromisos y valores vinculados al trabajo y la productividad.

Como se señaló, en Chile el paternalismo industrial ha sido visibilizado principalmente en el desarrollo, auge y declive de los campamentos mineros del Norte Grande, vinculados al salitre o el cobre, o en la industria del carbón en la Cuenca de Arauco y su desarrollo urbano ligado a la extracción del mineral (Venegas, 2008). Para los poblados de Lota y Coronel, Venegas (2015) analizó las estrategias de control social durante la primera mitad del siglo XX, examinando cómo el paternalismo industrial construyó un horizonte utópico que incidió en modelar la vida de cientos de trabajadores y sus familias. Estas experiencias paternalistas se manifestaron simultáneamente en otros rubros y ámbitos del Gran Concepción, como en la Sociedad Nacional de Paños de Tomé. Venegas y Morales (2017) sostienen que entre 1913 y 1940 “(...) su plana directiva propició la adhesión y 
lealtad de sus operarios reclutando familiarmente a los nuevos trabajadores y proporcionando en forma selectiva vivienda gratuita. Con ello buscó integrar a los operarios textiles a una 'comunidad' dirigida por la Oficina de Previsión Social" (p. 273).

Centrando el análisis en el espacio productivo, social y urbano surgido del modelo fordista promovido por el Estado chileno, y específicamente sobre la conformación de barrios obreros y villas industriales durante la segunda mitad del siglo XX, Brito y Ganter (2015), a partir de la problematización del diseño urbano de las viviendas construidas para los trabajadores de la planta Siderúrgica Huachipato, instalada a finales de la década de 1940 en el Gran Concepción, develaron cómo los regímenes familiares y su expresión en la modelación de espacios habitacionales

(...) se hacen funcionales a las particularidades del modelo de desarrollo, tanto en una escala productiva como en una urbana, y requieren de una intervención que se expresa, desde arriba con las políticas macroeconómicas $\mathrm{y}$, desde abajo con las formas particulares de intervenir y modelar los espacios privados que constituyen el barrio y la vivienda (p. 11).

Previamente, los mismos autores habían observado la existencia de un potente arraigo donde el barrio se convierte en un espacio vivencial y experiencial, pues los habitantes desean seguir viviendo en los lugares en donde han ido forjando su memoria social (Brito y Ganter, 2014). Fuentes y Pérez (2018) han llegado a señalar que la Compañía de Acero del Pacífico (CAP) llegó a instaurar un modelo urbano habitacional en la intercomuna de Concepción, materializado en una serie de intervenciones que instalaron un modo de habitar arquitectónico y urbano inspirado en la arquitectura moderna, cuyos resultados “(...) apropiaron en la escala intermedia una imagen y un uso contemporáneo adaptado y repetible. Su imagen asociada a la unidad vecinal se propagó por la zona instaurando un lenguaje prototípico" (p. 74). Estos autores apuntan la presencia de cuatro tipologías de espacios residenciales generados por la acción paternalista de esta empresa estatal: el encaje sobre la ciudad tradicional, la primera ciudad funcional en Chile, las unidades vecinales y los conjuntos segregados. Asimismo, destacan que el paternalismo, el cooperativismo y la movilidad social son factores influenciados por el control, el poder y la identidad. También para la Región del Biobío, Pérez y Fuentes (2019) mostraron cómo la industria del papel -privada y mixta- de la segunda mitad del siglo XX materializó conjuntos habitacionales de marcado carácter colectivo, ya sea mediante la acción pa- 
ternalista o cooperativa: el recinto FACELA (Fábrica Celulosa Laja) en Laja, el conjunto Papeles Bío-Bío en San Pedro de La Paz, y los conjuntos Coinac y J. Durán en la ciudad de Nacimiento. Todos ellos quedaron conectados a sus industrias originarias y con el río Biobío como presencia determinante.

En la Región de Magallanes se ha relevado el paternalismo industrial propiciado por el Estado, tanto desde el punto de vista histórico y social como del poblamiento y desarrollo industrial, con especial atención en los campamentos de ENAP en Tierra del Fuego (Acevedo y Rojas, 2015a). Cvitanic y Matus (2019) han enfatizado en las particularidades del hábitat colectivo, presentando la arquitectura de la vivienda de todos los campamentos y barrios del petróleo de esta región austral, como una dimensión relevante en la construcción del patrimonio industrial asociado a la actividad de la ENAP entre 1945 y 1972.

Nuestro trabajo, alineado con esa tendencia, busca elementos que ayuden a esclarecer las formas de operar industrial que asentaron comunidades barriales o vecinales bajo el manto del paternalismo propiciado por el Estado, en el Gran Concepción.

\section{INDUSTRIALIZACIÓN Y ACCIÓN HABITACIONAL EN LA ENAP: EL CASO DE LA REFINERÍA BÍO BÍO}

En la industrialización promovida por el Estado se identifican dos momentos. El primero es abordado por las políticas económicas del gobierno de Carlos Ibáñez del Campo (1927-1931), y el segundo fue el proceso de la Industrialización Sustitutiva de Importaciones, en el cual el Estado -a través de la Corporación de Fomento de la Producción (CORFO)- es el encargado de promover el desarrollo industrial, tanto de carácter estatal como de iniciativa privada. Este segundo momento posibilita la creación de la Empresa Nacional del Petróleo.

Si bien Acevedo y Rojas (2015a; 2015b) han atendido parcialmente el registro histórico y social, y Hecht (2002) y Domínguez (2011), la expresión arquitectónica y paisajística de la acción de la ENAP en Magallanes, Matus y Cvitanic (2016) han sido quienes han precisado que para este territorio la empresa diferenció dos realidades o escalas de actuación: “(...) el problema de la vivienda en aquellos lugares donde se localizaba la actividad productiva y el problema de la vivienda de los empleados y obreros que trabajaban y habitaban en Punta Arenas (...)" (p. 131). Esta segunda situación fue aplicada en el Gran Concepción, localizando conjuntos habitacionales en 
torno a las vías estructurantes de la naciente área metropolitana, configurando un sistema tentacular (Fuentes y Pérez, 2012).

En el mismo sentido, para el Gran Concepción resulta aplicable lo que Matus y Cvitanic (2016) señalan:

(...) fueron los empleados y los obreros quienes tuvieron grados de libertad para elegir, [sic] donde vivir, en función no sólo de su poder adquisitivo, sino que también en función de una estructura que lentamente se institucionalizó por medio de reglamentos y se inscribió tanto en objetivos de la empresa como en el contexto del desarrollo histórico de la vivienda económica en Chile. (p. 133)

La Empresa Nacional del Petróleo fue creada mediante Ley No 9.618 del 19 de junio de $1950^{1}$, luego del descubrimiento del primer pozo de petróleo en la Región de Magallanes, en diciembre de 1945, en un sector denominado Spring Hill ${ }^{2}$. Una de las primeras acciones de la empresa fue construir en 1954 la Refinería de Petróleo de Concón, actualmente Refinería Aconcagua. En 1959 se construyeron instalaciones para el almacenamiento y distribución de combustibles refinados en Maipú (Región Metropolitana de Santiago) y, al año siguiente, la terminal marítima de Gregorio, en Magallanes. En 1962 entró en operación la Planta de Gasolina de Cullen en la misma región; luego, la inauguración de la segunda gran refinería del país, en la Región del Biobío -actualmente Refinería Bío Bío. Emplazada en Talcahuano (actual comuna de Hualpén), comenzó a operar en julio de 1966, con una capacidad de refinación de $5.770 \mathrm{~m}^{3}$ diarios y 250 trabajadores (I. Municipalidad de Hualpén, 2017). En Chile, el sector hidrocarburos tiene un rol crucial en la producción de energía primaria y es el más relevante dentro de la matriz energética (Agostini y Saavedra, 2009).

\footnotetext{
${ }^{1}$ Es una empresa pública de propiedad del Estado de Chile, cuyo giro principal es la exploración, producción, refinación y comercialización de hidrocarburos y sus derivados. Opera como empresa comercial, con un régimen jurídico de derecho público y se administra en forma autónoma. Ver página web de la empresa, descripción (http://www.enap.cl/pag/509/1572/descripcion).

${ }^{2}$ El hallazgo de petróleo dio paso a perforaciones de nuevos pozos que resultaron productivos, por lo que la Corporación de Fomento de la Producción (CORFO) decidió la creación de ENAP, para explotar comercialmente los yacimientos descubiertos en Magallanes (cf. página web de la empresa: http://www.enap.cl/pag/100/776/historia).
} 


\section{ACCIÓN HABITACIONAL DE REFINERÍA BIO BÍO}

Esta planta originó una demanda habitacional para trabajadores externos a la empresa, quienes comenzaron a instalarse en sus cercanías. Así, parte del personal que laboró en la construcción fue traspasado a la planta, creando una sección, radicada posteriormente en la de Bienestar, formando un Plan Habitacional. La gerencia logra que se le asigne una población CORVI, cercana a la refinería para su personal de emergencias ${ }^{3}$ (J. Cienfuegos, comunicación personal, octubre 2017). Esta y otras poblaciones forman parte de un plan de regeneración urbana patrocinado por la Refinería ${ }^{4}$, que espera mitigar los efectos originados por los contaminantes ambientales presentes en esta área del Gran Concepción.

La obra habitacional auspiciada por ENAP en el Gran Concepción asumió variados tipos de gestión ${ }^{5}$, uno de ellos fue un extenso conjunto habitacional promovido por iniciativa de trabajadores de la empresa, iniciado en 1970 en San Pedro de Coronel, denominado Villa Spring Hill.

Los conjuntos habitacionales se situaron lejanos a la refinería. Tal emplazamiento implicó un cambio de estrategia productiva y en consecuencia urbana, en consideración a los principios de la industria fordista, donde el trabajador y su familia forman parte de la cadena productiva, pero con independencia funcional y espacial de la planta. Aquí la industria contribuye al surgimiento de un grupo social que participa del concepto de casa propia instalado por organismos del Estado, entre ellos la Corporación de la Vivienda (CORVI). Se enaltece el imaginario de la propiedad como principio de realización material y como ingreso a una sociedad urbana. Por sus características -sociales, espaciales, formales y de gestión- este trabajo repara en Villa Spring Hill, cuya primera etapa fue inaugurada en 1971.

\footnotetext{
${ }^{3}$ La empresa gestionó la asignación de otra población adyacente a la planta, para parte del personal. Así, hacia 1968 las poblaciones Irene Frei y 18 de Septiembre formaron parte de "La Emergencia", en un sector que había comenzado su poblamiento en la década de 1960, debido a la necesidad de trabajadores de ENAP, pero también de otras plantas como Huachipato, INCHALAM o Gacel, dado el déficit habitacional existente, incrementado por el terremoto de 1960 (J. Cienfuegos, comunicación personal, octubre 2017).

${ }^{4}$ Conocido oficialmente como Hualpén Suma, que impulsa ENAP en conjunto con el Gobierno Regional y la Municipalidad de Hualpén.

${ }^{5}$ Incluyó también la construcción de un edificio de 4 plantas en el centro de Concepción -esquina de calles Salas y Freire- y dos conjuntos habitacionales localizados en las comunas de Concepción (hoy Chiguayante) en 1969 y Coronel en 1976 (actualmente, San Pedro de la Paz).
} 


\section{VILLA SPRING HILL. BARRIO JARDÍN A ORILLAS DEL BIOBÍO}

Es un conjunto habitacional de gran escala emprendido por trabajadores agrupados en torno al Sindicato ENAP Talcahuano, localizado en la ribera sur del río Biobío, frente a las instalaciones, en un sector plano conectado con la industria, primero a través del Puente Viejo y posteriormente del Puente Juan Pablo II. El conjunto corresponde a un período donde las políticas empresariales externalizan la vivienda para sus trabajadores, concibiéndose esta como servicio independiente del componente productivo.

\section{Diseño del conjunto}

La gestión de la urbanización y la vivienda fue liderada por trabajadores organizados, quienes habían adquirido diversos paños adyacentes al río Biobío (J. Cienfuegos, comunicación personal, octubre 2017). Su financiamiento fue logrado en términos cooperativos y el diseño desarrollado por etapas, de las cuales la tercera fue abordada por los arquitectos Sergio Larraín G.-M., Ignacio Covarrubias y Jorge Swinburn. La primera etapa fue inaugurada el 12 de febrero de 1971 (J. Cienfuegos, comunicación personal, octubre 2017) y la segunda en 1972. En su ejecución participó la Empresa Constructora Morales Jeldres y en la supervisión de las obras por parte de ENAP, el constructor Jorge Cienfuegos, funcionario del Departamento de Bienestar. En la $3^{\mathrm{a}}$ y $4^{\mathrm{a}}$ etapas continuó supervisando por la empresa el constructor Luis Unda (J. Cienfuegos, comunicación personal, octubre 2017).

La organización de la Villa corresponde a una extensa franja paralela al río flanqueada al sur por la Avda. Enrique Soro, que conecta con el Puente Juan Pablo II (acceso expedito a la industria al otro lado del río), y la calle Violeta Parra, costanera al costado del río Biobío, por el norte. Esta franja posee dos sectores articulados por un área de equipamientos entre la $2^{\mathrm{a}}$ y la $3^{\text {a }}$ etapa, aunque posteriormente no fue consolidada. (Fig. 1) 


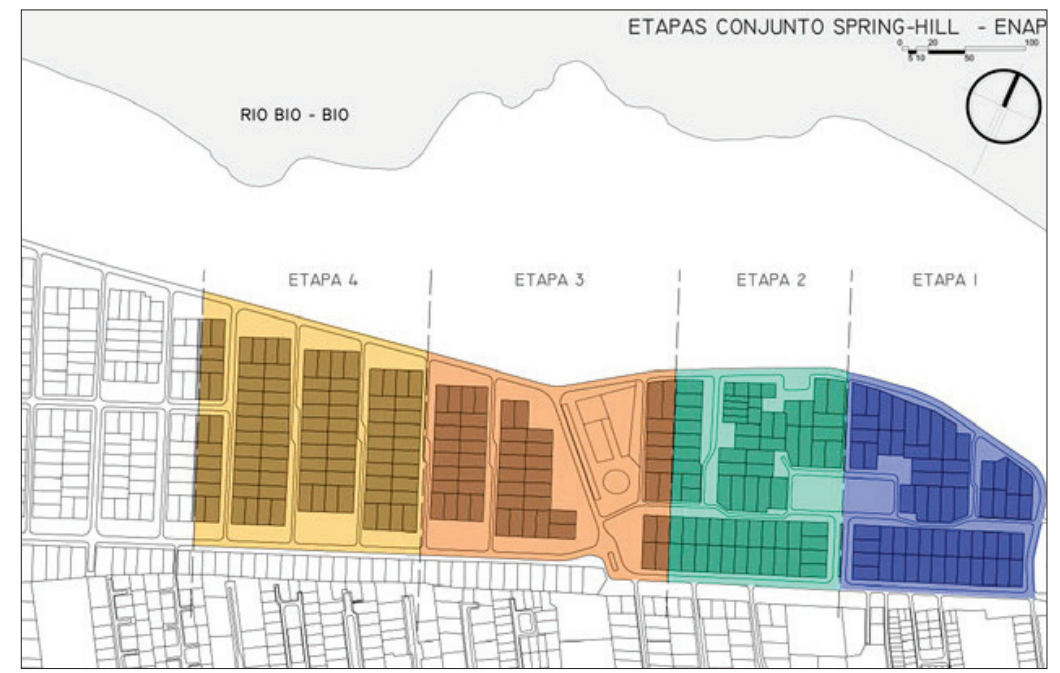

Figura 1. Etapas Villa Spring Hill. Fuente: elaboración propia. Dibujo: F. Cisternas.

El sector oriente, que corresponde a las etapas 1 y 2 (Fig. 2) es más variado en su distribución espacial discontinua de calles, pasajes y plazoletas. El sector poniente, de las etapas 3 y 4 es más homogéneo, se distribuye en sucesivos pasajes paralelos dirigidos al río, conformados por generosos antejardines que anteceden a las viviendas (Fig. 3). Se construyeron aproximadamente 400 casas.

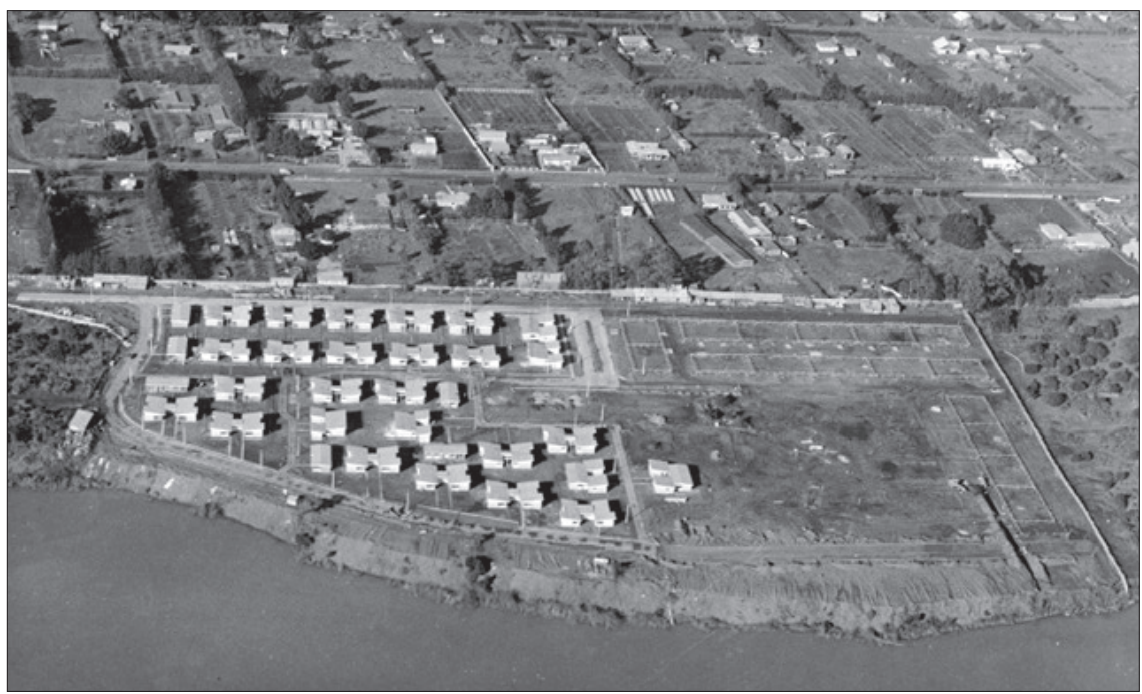

Figura 2. Vista aérea $1^{\text {a }}$ etapa y trazados $2^{a}$ etapa, circa 1971. Fuente: Archivo L. Pérez. 


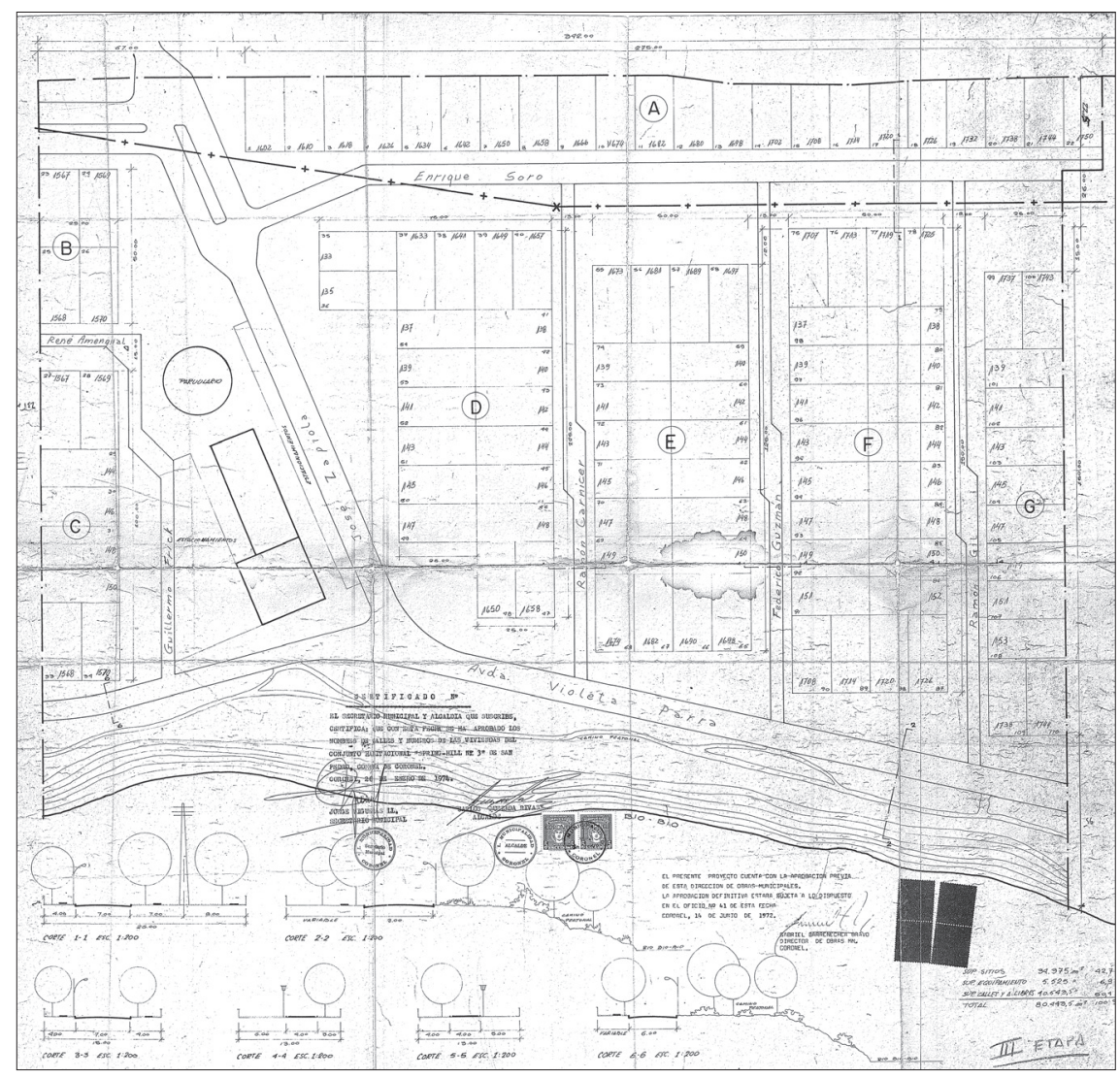

Figura 3. Plano $3^{a}$ etapa, 1972. Fuente: Archivo D.O.M. Municipalidad de San Pedro de la Paz.

\section{Tipología arquitectónica}

El proyecto de vivienda fue mandatado a los arquitectos Rosa Aparicio, Augusto Iglesias y Jorge Le Roi. Su financiamiento se consiguió mediante un préstamo individual a 20 años, otorgado por la Asociación de Ahorro y Préstamo Andalién ${ }^{6}$. Las viviendas son de una planta y pareadas, de un

\footnotetext{
${ }^{6}$ Las Asociaciones de Ahorro y Préstamo fueron instituciones privadas constituidas como sociedades mutuales que se encargaban de la captación de clientes bajo depósitos de ahorros y emitían títulos de deuda. Estaban reguladas por la Caja Central de Ahorro y Préstamos, junto a la cual formaron parte del Sistema Nacional de Ahorro y Préstamo, sistema financiero creado para la adquisición de viviendas mediante un sistema de ahorro que funcionó entre 1960 y 1980 (Hidalgo, 2019).
} 
único tipo residencial (Figs. 4 y 5), aunque con tres tamaños de planta, viviendas que comparten en su centro tanto el espacio de acceso como el de antejardín, fomentando el encuentro vecinal. Es una opción con pretensiones sociales homogeneizadoras que aspiran a nivelar a los estamentos trabajadores y, por consecuencia, a integrarse en el espacio urbano. El estatus social y laboral de los residentes es homogéneo, unificando así un sentido de clase, donde no comparecen obreros ni cargos de alta dirección. (Fig. 6)

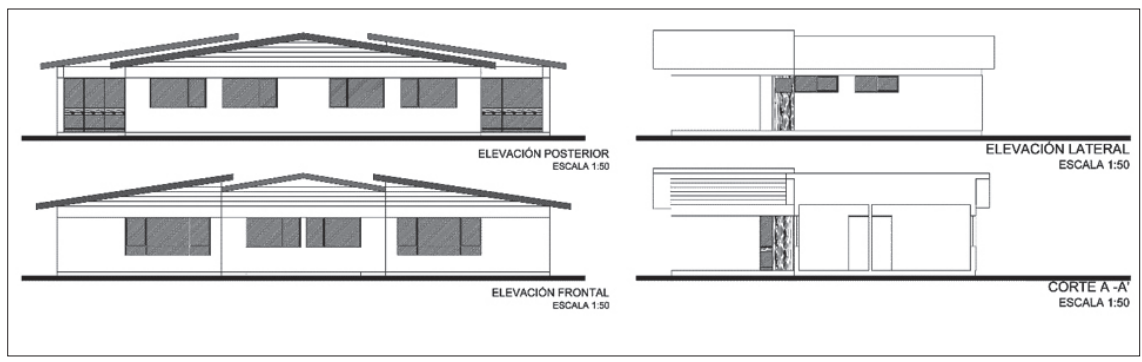

Figura 4. Elevación frontal y posterior vivienda Spring Hill, tipo 3. Fuente: elaboración propia. Dibujo: F. Cisternas.

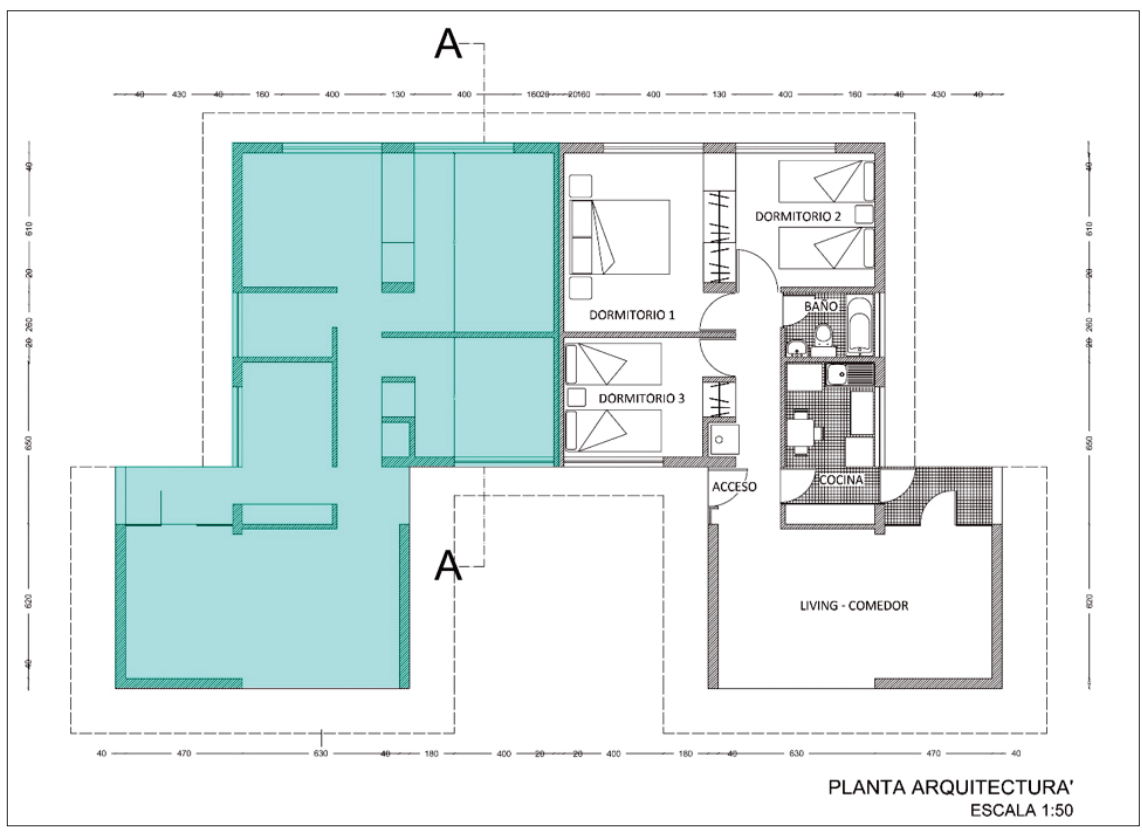

Figura 5. Planta vivienda Spring Hill, tipo 3. Fuente: elaboración propia. Dibujo: F. Cisternas. 


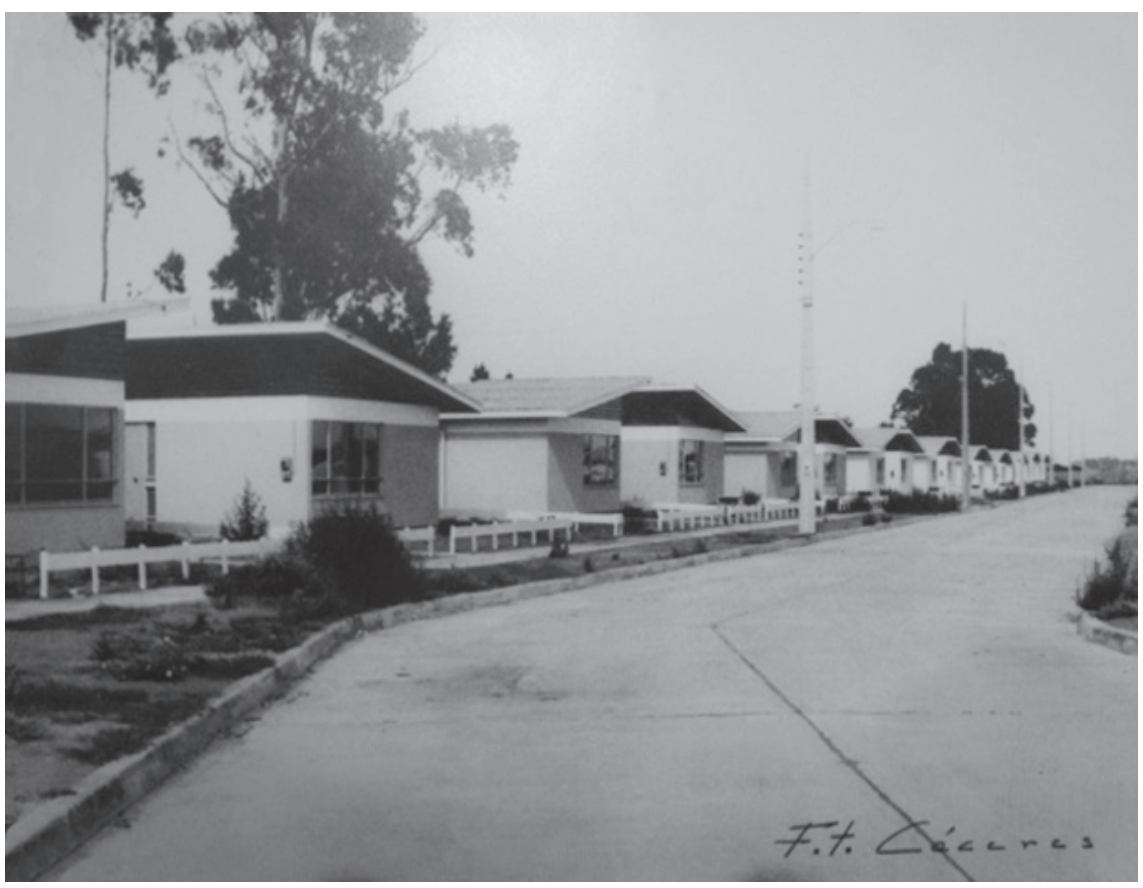

Figura 6. Agrupamiento de viviendas y antejardines en manzanas lineales, inauguración $1^{\text {a }}$ Etapa (12.02.1971). Fuente: Archivo: J. Cienfuegos.

\section{Tejido social urbano}

El tejido social está vinculado con la concepción y diseño del espacio urbano. Villa Spring Hill corresponde a una gestión cooperativa de producción de vivienda, donde predomina la acción del trabajador como gestor y propietario. El conjunto, transformado posteriormente en barrio, fue una iniciativa respaldada por la empresa, que apoyó económicamente el proyecto porque era conveniente a sus intereses. En palabras de ex trabajadores enapinos que forman parte de la Villa, se señala que ${ }^{7}$ :

Ahí fue que el Sindicato se consiguió un préstamo. La Asociación de Ahorros y Préstamos Andalién estaba en Concepción. Entonces, para que alguien tuviera una escritura y pagara si se retiraba, estaban ENAP

\footnotetext{
${ }^{7}$ En el siguiente apartado se exponen citas textuales de ex trabajadores enapinos que habitan la Villa Spring Hill, extraídas de entrevistas inéditas realizadas por R. Herrera, en el marco de la investigación.
} 
y la Asociación. (...) Y cuando se despedía, se descontaba la deuda y después lo que quedaba, para el trabajador. Igual con la jubilación.

(...) Y cuando nació la idea, que yo creo que fue tanto de la empresa como de la gente, aunque más de la gente, diría yo, se empezó a buscar el terreno. (...). Da la impresión que ellos calcularon que les estaba saliendo muy caro el tema y no había mayor control. Entonces dijeron mejor apoyar la compra de un terreno dando un préstamo para eso, así se tenía un montón de gente en un mismo lugar, y se mataban dos pájaros de un tiro, porque se solucionaba también el tema del transporte. (C. Fuenzalida, comunicación personal, 2 de agosto 2017)

ENAP, respaldando la iniciativa, realizó los préstamos traspasados luego a la Cooperativa de Ahorro y Préstamos Andalién. También estableció el tipo de construcción asociado a las viviendas:

Era puro arenal al principio, y algunos estuvieron de acuerdo, aunque otros no. Pero se llevó adelante la compra. Se parceló, se dividieron los terrenos y nos llamaron a una reunión donde había una cantidad de papelitos con números, que eran los números de los sitios... Lo hicimos nosotros, la empresa miraba desde el lado no más. Y entonces se empezó a construir la primera etapa y se juntó una plata para hacer jardines y todo eso. Después ya se hizo una segunda etapa. Y hasta allí llegamos nosotros como Comité. Ya después la empresa vio con buenos ojos lo que había, la buena organización, que era relativamente barato y cerca de la empresa y se metió más en las tercera y cuarta etapas. (C. Fuenzalida, comunicación personal, 2 de agosto 2017)

Según estos testimonios, el acceso a la vivienda se entiende como en correlato a los beneficios del trabajar en ENAP, a diferencia de otras empresas de la zona. De este modo, sería indisociable de este privilegio la posibilidad de cambiar la vida del trabajador, girando en torno a la familia y a la posibilidad de asentarse en un lugar permanente.

Pero en la ENAP de partida se tenía mejor sueldo, había más recursos. También estando en la ENAP se pudo conseguir casa, cosa que en los otros trabajos no se presentó ...

(...) Lo que si es que lograr entrar a la ENAP significaba la posibilidad de proyectarse. Proyectar la casa, proyectar los hijos, proyectarse ya para el matrimonio y para unos 20 a 30 años para adelante. (H. Morales, comunicación personal, 2 de agosto 2017)

Si bien el rol del sindicato es fundamental, y ampliamente reconocido por los logros conseguidos por los trabajadores, los distintos testimonios 
destacan la confluencia de intereses entre los diferentes estamentos que componían la empresa. Trabajadores y jefaturas, por mediación del sindicato, lograron importantes avances que articulaban las necesidades de los empleados y la empresa. Esto ocurrió cuando el proceso de producción industrial se extendía desde los espacios de trabajo a los del no-trabajo. La empresa era una entidad con rostro humano, personas naturales que aparte de sus rangos, eran conocidos.

Se erige así un conjunto habitacional capaz de reproducir estas relaciones dentro de la empresa. En Villa Spring Hill se escenifican valores sociales compartidos por sus habitantes. Su construcción es una variante del influjo de ciertos principios de la arquitectura moderna que instalaban al arquitecto como un reformador social, y a la obra arquitectónica como instrumento para estructurar los lugares donde se desarrollan las funciones vitales humanas. Dentro de este marco estaba la vivienda familiar, donde el trabajador desarrollaba su conciencia de clase, sin oponerse a los intereses de la empresa.

Hay que considerar que los que se vinieron a vivir aquí eran los trabajadores. Porque los jefes e ingenieros se fueron a otros sectores, Pedro de Valdivia, cerro La Virgen, lugares que eran top en esos años en Concepción. (...) Ya entre la segunda y la tercera etapa aparece Rucalhue, en el camino a Santa Juana, pero los otros se fueron independientes buscando sus casas. (P. Barrales, comunicación personal. 2 de agosto 2017)

ENAP no tiene una presencia cotidiana en Spring Hill, pero sí valores asociados que fomentan un trabajador consciente de su condición. Tolerancia, respeto y obediencia son determinantes para el ambiente laboral, y también para la formación del buen vecino, de acuerdo a un proceso de instrucción y regulación social iniciado cuando el trabajador ingresa a capacitarse a la industria y se extiende hasta la convivencia barrial en la Villa.

Entonces vivir en un barrio así, donde además todos son compañeros de trabajo, y te los topas en los comedores o en el trabajo (...). Esto de ser vecino y compañero de trabajo es algo único. Ya después uno puede dejar de ser amigo de algunos o puede alejarse. Pero nunca dejas de ser compañero de trabajo (B. Lozada, comunicación personal, 5 de diciembre 2017)

Entonces se enfatizan aspectos de convivencia urbana que reflejan el privilegio de ser parte de aquel mundo. Sobresalen las fachadas exteriores similares -que ocultan las diferencias internas-, las plazas interiores donde 
se encuentran padres e hijos en igual condición, casas sin rejas que promueven la vecindad, por sobre las diferencias entre unos y otros. El sentido de igualdad en el mundo residencial brinda una sensación de armonía y comodidad.

Estuvimos como 10 años viviendo sin cercos, todo abierto, dejando las bicicletas ahí mismo. Uno podía irse de vacaciones tranquilo y al volver estaba todo igual. Y venían los buses a buscarnos hasta acá y después nos traían al final del turno. (B. Lozada, comunicación personal, 5 de diciembre 2017)

A las comodidades ofrecidas en el ámbito laboral se suman cualidades del mundo doméstico inherentes a la vida barrial ligadas a la empresa. Las comodidades y retribuciones vinculan a los trabajadores con la idea de desempeño, mientras que el barrio vincula a este y su familia con la industria. Esta característica permitía el desarrollo de una categoría social de escala barrial, un diferenciador positivo frente al resto de la ciudad y sus habitantes. El barrio como escenario espacial de la vida social es la proyección de los intereses paternalistas de la industria.

Si bien el proceso de industrialización en el Biobío fomentó la llegada de gente proveniente de distintas zonas, la oferta de trabajo en la industria y vida barrial asegurada, acaba por igualarlos, cuestión que creó un sentimiento de pertenencia a ENAP. Se contienen así potenciales conflictos, reforzando la idea de una comunidad homogénea cuyo espíritu resalta aquello que los pone en común por sobre lo que los diferencia. Igualdad y vecindad se escenifican en la fiesta de Navidad, del día de la Independencia, del día del petróleo, celebraciones empresariales que integraban al trabajador y su familia; pero también en la dinámica del trabajo diario, canalizado por el aprendizaje del funcionamiento de cada sección de la industria, de manera de conocerla entera, aprehendiéndola como un conjunto.

Se trata de un proyecto social que implicaba convertirse en refinero, y también vecino que convive "entre" refineros. La anulación de las diferencias sociales en el barrio promueve un espíritu común centrado en torno a las cualidades reafirmadas por la empresa y su idea de buen trabajador buen vecino. En el trabajo, el reconocimiento era el ascenso interno; en el barrio, era la buena convivencia familiar y colectiva.

Se traslada a la vida vecinal valores sociales predominantes en el mundo laboral; es una manera de extender la disciplina industrial al ámbito barrial y doméstico, respondiendo al principio del paternalismo industrial que se sintetiza en el habitus (Bordieu y Wacquant, 2005) ${ }^{8}$ del trabajador, más allá 
del trabajo. Es interesante advertir las formas en que ese proceso se internaliza en el comportamiento de los trabajadores-vecinos, constatando sus visiones, percepciones y vivencias. Este sentido de pertenencia arraigado supera a los habitantes de la Villa y se extiende a aquellos que recibieron casas fuera del barrio, pero que en su condición de enapinos o refineros formaban un tejido social sustentado en códigos sociales compartidos:

Nosotros nos reconocemos donde estemos...y siempre nos miramos todos como iguales, entonces tú te encuentras con alguien que alguna vez te arregló algo, que te ayudó en tal cosa, tú a ese te lo encuentras afuera en la calle y lo saludas con un abrazo. Esa era la forma de relacionarse. (C. Castro, comunicación personal, 2 de agosto 2017)

Para los trabajadores de ENAP, Villa Spring Hill significa un hito fundamental de la relación empresa-trabajadores. También hubo otros conjuntos, en otras partes de la provincia que igualmente dieron solución habitacional a otros trabajadores de la empresa. Villa Spring Hill establece un origen común y compartido a través de un tejido urbano. El espíritu refinero o enapino es más inclusivo y abarca un conjunto difuso de lugares y personas que forman parte de este mundo social desarrollado desde los años 60 en el Gran Concepción.

\section{CONCLUSIÓN}

La gestión habitacional de Villa Spring Hill fue una operación de impulso mixto que evidencia el papel y escala de la modernización fiscal en los años 70 del siglo pasado. El Comité de la Vivienda implementado por ENAP responde a un modelo de gestión cooperativa donde se advierte la autonomía de los trabajadores. La ENAP aparece en la $1^{\mathrm{a}}$ y $2^{\mathrm{a}}$ etapa con un rol secundario -aunque relevante en la medida en que poseía el capital. En la $3^{\text {a }}$ y $4^{\text {a }}$ etapa se evidencia su papel constructor de tejido urbano. Ya no es solo cooperar para edificar, sino también dar continuidad a un plan de urbanización. Es destacable el rol que la empresa cumple en las primeras dos etapas, las de mayor autonomía, cuando a pesar de su rol capitalista y observante de un proceso, también ofrece elementos indispensables -léase

\footnotetext{
${ }^{8}$ Expresión de una racionalidad práctica individual que actúa como mecanismo estructurante de la vida social, otorgándole regularidad.
} 
experticia técnica y maquinarias-, con el afán de apoyar una urbanización que no planificó, pero que incorporó paulatinamente.

Desde el enfoque de los propietarios de la Villa, los pasajes les permiten a sus pobladores la vida colectiva en microcomunidades pareadas, donde todos se reconocen como iguales. Es una suma de unidades vecinales entre las cuales los pasajes nuclearizan y fomentan el uso peatonal de la Villa sobre el vehicular.

Es sugerente la forma en que se verbaliza la relación entre intereses que destacan la mancomunión empresa-trabajadores. Se asume la idea de una gran familia refinera, donde la industria ocupa un lugar no preponderante en el desenvolvimiento de lo cotidiano, aunque relevante en su gestación y concreción. Una gran familia donde cada quien sabe su lugar y desempeño correspondiente. Los trabajadores, con conciencia de tener privilegios laborales, admiten el amparo de una institucionalidad implícitamente protectora. Los patrones resguardan valores asociados al desempeño en el trabajo, que inciden en la productividad a partir de un compromiso colectivo orientado al éxito de ENAP.

Es un Paternalismo Estatal como modelo productivo que creó, más allá de la industria, modelos de comportamiento hasta hoy defendidos y anhelados. Hoy se advierte una mirada crítica al presente asentado sobre valores perdidos o alterados, donde trabajadores y ex trabajadores lo refrendan en el espacio barrial y doméstico.

La morfología urbana escenifica valores sociales de quienes allí habitan. El espacio social se vuelve preponderante por sobre el ámbito laboral, reflejando extensiones simbólicas del paternalismo traspasados a las prácticas y valoraciones de los habitantes que exceden el marco de la empresa.

Sin embargo, todo un cúmulo de evaluaciones negativas quedan desplazadas, por efecto de esta combinación de compromiso, agradecimiento y respaldo que implica que una empresa de orden estatal apoye y promocione instancias que exceden el ámbito laboral y permiten a una masa laboral consolidar una vida social y material destacada.

Queda pendiente adentrarse en los pormenores de estos marcos de construcción de la experiencia social que permean el discurso sobre el pasado, para dilucidar patrones que llevan a la elaboración de paisajes ideales que el presente ya no alberga. Aceptando la fuerte incidencia del paternalismo como práctica, queda por dilucidar la incidencia de los trabajadores en la configuración de un presente. El paternalismo se revela como el ocaso de una época marcada por la industrialización, la urbanización y la habituación. 


\section{REFERENCIAS}

Acevedo, P. y Rojas, C. (2015a). Campamentos enapinos en Tierra del Fuego. Perspectivas desde el patrimonio industrial. Sophia Austral, 14, 85-97. Recuperado de http://www.sophiaaustral.cl/index.php/shopiaaustral/article/ view/7

Acevedo, P. y Rojas, C. (eds.) (2015b). Enapinos. Los campamentos petroleros del Fin del Mundo. Un Patrimonio Industrial por armar. Santiago de Chile: Consejo Nacional de la Cultura y las Artes. Recuperado de http://www.historia396.cl/index.php/historia396/article/view/56

Agostini, C. y Saavedra, E. (2009). La industria del petróleo en Chile. Estudios Públicos, 114, 163-218.

Archivo Jorge Cienfuegos, Villa Spring Hill, Fotografía B/N. https:/www.cepchile.cl/la-industria-del-petroleo-en-chile/cep/2016-03-04/094942.html

Bourdieu, P. y Wacquant, L. (2005). Una invitación a la sociología reflexiva. Buenos Aires, Argentina: Siglo XXI.

Brito, A. y Ganter, R. (2014). Ciudad obrera: persistencias y variaciones en las significaciones del espacio. El caso de la siderúrgica Huachipato y su influencia en el desarrollo urbano del Gran Concepción, EURE, (40)121, 2953. Recuperado de https://dx.doi.org/10.4067/S0250-71612014000300002

Brito, A. y Ganter, R. (2015). Cuerpos habitados, espacios modelados: el caso de la siderúrgica Huachipato, 1940-1970. Historia 396, 5 (1): 11-36. Recuperado de http://www.historia396.cl/index.php/historia396/article/view/56.

Cvitanic, B. y Matus, D. (2019). Vivienda y patrimonio industrial: los campamentos del petróleo en Magallanes. Sophia Austral, 23, 205-234. Recuperado de http://www.sophiaaustral.cl/index.php/shopiaaustral/article/view/ 255

Domínguez, P. (2011). Cerro Sombrero, arquitectura moderna en Tierra del Fuego. Santiago, Chile: Consejo Nacional de la Cultura y las Artes.

ENAP. Sitio web oficial de la Empresa Nacional del Petróleo. http://www.enap. cl/pag/100/776/historia. (Consulta: 22 de noviembre de 2017)

Fuentes, P. y Pérez, L. (2012). Formación del Concepción metropolitano a través de grandes conjuntos residenciales. Aportaciones del urbanismo moderno. Atenea, 505, 33-78. Recuperado de http://dx.doi.org/10.4067/S071804622012000100003

Fuentes, P. y Pérez, L. (2018). La Compañía de Acero del Pacífico, CAP. Instauración de un modelo urbano habitacional en la intercomuna de Concepción. INVI, 33(93), 71-96. Recuperado de http://revistainvi.uchile.cl/index. php/INVI/article/view/1155/1424

Garcés, E. (1999). Las ciudades del salitre: un estudio de las oficinas salitreras en la región de Antofagasta. $2^{\mathrm{a}}$ ed. Santiago, Chile: Orígenes.

Garcés, E. (2003). Las ciudades del cobre. Del campamento de montaña al hotel minero como variaciones del company town. Eure, $X X I X(88), 131-148$. http://dx.doi.org/10.4067/S0250-71612003008800006 
Garcés, E., Cooper, M. y Baros, M. (2007). Las ciudades del cobre: Sewell, Chuquicamata, Potrerillos, El Salvador, San Lorenzo, Pabellón del Inca y Los Pelambres. Santiago, Chile: Universidad Católica de Chile.

Godoy, M. (2015). Las casas de la empresa: Paternalismo y construcción de espacio urbano en Chile. Lota, 1900-1950, Universum, 30(1), 115-136. Recuperado de http://dx.doi.org/10.4067/S0718-23762015000100008

Hecht, R. (2002). Trazado, paisaje y territorio: Cerro Sombrero y la arquitectura del petróleo en Magallanes. $A R Q, 51,64-67$. Recuperado de https:// dx.doi.org/10.4067/S0717-69962002005100016

Hidalgo, R. (2019). La vivienda social en Chile y la construcción del espacio urbano en el Santiago del siglo XX. Santiago, Chile: RIL Editores.

I. Municipalidad de Hualpén. Sitio web. http://www.hualpenciudad.cl/noticia_aniversario_enap.html (Consulta: 22 octubre de 2017).

Mantecón, T. (2010). Formas de disciplinamiento social, perspectivas históricas, Historia Social y de las Mentalidades,14(2), 263-295. Recuperado de http://www.revistas.usach.cl/ojs/index.php/historiasocial/article /view/241

Matus, D. y Cvitanic, B. (2016). La Empresa Nacional del Petróleo y la construcción de un paisaje urbano: barrios de la ciudad de Punta Arenas, En: Navarro, V. y Ciselli, G. (eds.), Paisajes culturales y patrimonio: expresiones de la cultural territorial (pp. 130-136). Río Gallegos, Argentina: Universidad Nacional de la Patagonia Austral. Recuperado de http://www.repotur. gov.ar/handle/123456789/7008

Pérez, L. y Fuentes, P. (2019). Habitar colectivo en las riberas del Biobío. Enclaves residenciales de la industria del papel, Cuadernos de vivienda y urbanismo, 12(23), 1-21. Recuperado de https://revistas.javeriana.edu.co/filesarticulos/CVU/12-23\%20(2019-I)/151558490003/

Sierra, J. (1984). De las utopías socialistas a las utopías patronales: para una genealogía de las disciplinas industriales paternalistas, REIS, 26, 29-44.

Sierra, J. (1985). Políticas de Vivienda y Disciplinas Industriales Paternalistas en Asturias. ERIA. Revista cuatrimestral de Geografía, 8, 61-71.

Sierra, J. (1990). El obrero soñado. Ensayo sobre el paternalismo industrial (Asturias, 1860-1917). Madrid, España: Siglo XXI.

Venegas, H. (1998). Desafíos de la industria carbonífera en Chile. Intervención del sector público en la senda del Estado Benefactor 1920-1940. Revista de Historia (Universidad de Concepción), 8, 151-173.

Venegas, H. (2008). El Carbón de Lota. Textos y fotografías a fines del siglo XIX. Las visiones de Francisco Marcial Aracena y Guillermo E. Raby. Santiago, Chile: Pehuén.

Venegas, H. (2015). Paternalismo industrial y control social. Las experiencias disciplinadoras en la minería del carbón en Chile, Lota y Coronel en la primera mitad del siglo XX. Amérique Latine Histoire et Mémoire. Les Cahiers ALHIM, 28. Recuperado de http://journals.openedition.org/alhim/5099

Venegas, H. y Morales, D. (2017). Un caso de paternalismo industrial en Tomé: Familia, espacio urbano y sociabilidad de los obreros textiles (1920-1940), 
Historia, 1(50), 273-302. Recuperado de http://revistahistoria.uc.cl/index. $\mathrm{php} / \mathrm{rhis} /$ article/view/132/127

Vergara, Á. (2013). Paternalismo industrial, empresa extranjera y campamentos mineros en América Latina: un esfuerzo de historia laboral y transnacional, Avances del Cesor, 10, 113-128. Recuperado de https://rephip.unr. edu.ar/xmlui/handle/2133/12810 